\title{
Educação de Jovens e Adultos na Cultura Digital
}

\section{Youth and Adult Education in the Digital Culture}

Resumo: O presente trabalho foi realizado com turmas de oitavos e nonos anos da Educação de Jovens e Adultos (EJA) numa escola municipal. A escolha dos temas partiu da necessidade de inclusão tanto digital quanto cultural visto que a maioria dos estudantes apresentava mínima ou até nenhuma formação digital e informação cultural sobre culinária africana. Buscamos aproximar os estudantes da tecnologia digital de maneira autoral, criativa e prazerosa, aliando a culinária africana e a matemática. A construção de blogs ocorreu para estender as relações e o contato com as tecnologias para além da sala de aula e hospedar as atividades da sobre a culinária africana, links de jogos matemáticos e tabelas de pesos e medidas. O presente trabalho foi uma construção coletiva do conhecimento onde todos se empenharam com alegria e vontade de querer aprender um pouco da cultura digital e dos saberes matemáticos.

Palavras-chave: Cultura digital. Blogs na Educação. Educação matemática. Etnomatemática.

\begin{abstract}
This study was conducted with groups of eighth and ninth years of the Youth and Adult Education (EJA) a municipal school. The choice of topics was based on the need to include both digital and cultural visa that most students had minimal or even no digital training and cultural information on African cuisine. We seek to bring students the digital copyright technology, creative and enjoyable way, combining African cuisine and mathematics. The building blogs occurred to extend the relationship and contact with the technologies beyond the classroom and host of activities on African cuisine, links to math games and tables of weights and measures. This work was a collective construction of knowledge where all engaged with joy and desire to want to learn a bit of digital culture and mathematical knowledge.
\end{abstract}

Keywords: Digital culture. Blogs in Education. Math education. Ethnomathematics.

BALDUINO, Grazielle Eloísa; SOUZA JUNIOR, Arlindo José de; SILVA, Iraides Reinaldo da. Educação de Jovens e Adultos na Cultura Digital. Informática na Educação: teoria e prática, Porto Alegre, v. 17, n. 2, p. 167-176, jul./dez. 2014.

\section{Grazielle Eloísa Balduino}

\author{
Arlindo José de Souza Junior
}

\section{Iráides Reinaldo da Silva}

Universidade Federal de Uberlândia

\section{Introdução}

0 presente trabalho partiu dos encontros coletivos oferecidos pelo curso de extensão Mídias nas aulas de Matemática realizado na Faculdade de Matemática com o apoio da Faculdade de Educação e Pró-Reitoria de Extensão Cultura e Assuntos Estudantis (PROEX-UFU). O curso Mídias nas Aulas de Matemática contou com o apoio financeiro da Fundação de Amparo a Pesquisa do Estado de Minas Gerais (FAPEMIG), tendo como objetivo propiciar aos professores do ensino fundamental a possibilidade de refletir sobre o processo 
de produção de saberes docentes, relacionados á utilização das Tecnologias de Informação e Comunicação (TICs) nos processos de ensinar e aprender Matemática.

Neste projeto foram envolvidos diversos profissionais da área da educação tais como: docente da universidade promotora, docentes das redes estadual, municipal e particular da cidade de Uberlândia (MG), pesquisadores, mestrandos e graduandos. Esta diversidade de profissionais nos possibilitou um aprendizado com os diferentes olhares e saberes na utilização das TICs para o desenvolvimento de atividades de Matemática. Uma dessas atividades foi à construção de um blog.

O blog é um recurso digital importante para o trabalho pedagógico do/a professor/a, e se apresenta como uma nova e dinâmica ferramenta de comunicação e aprendizado em conjunto com alunos/as, professores/as, escola e família. Busca despertar nos/as alunos/as a motivação, concentração, cooperação, respeito, responsabilidade estes são alguns dos preceitos que faz dessa ferramenta virtual um marco neste projeto. Portanto, implementar nas aulas de Matemática a ferramenta blog é poder ampliar os conceitos dos livros e construir com os/as alunos/as e toda a comunidade uma aprendizagem efetiva com vistas a sua inclusão no mundo da era digital. A seguir apresentamos a narrativa da professora regente da escola municipal envolvida diretamente neste trabalho educativo com os alunos e alunas.

Iniciamos os trabalhos numa escola municipal localizada na periferia da cidade de Uberlândia (MG) e, em conversas com os/as alunos/ as, todos/as moradores/as do bairro e arredores, demonstraram deslumbramento com o uso do computador, apesar de alguns não o ter em casa, mas utilizam as lan house do bairro. Assim, constatamos que o computador era usado somente para acessar páginas de msn, orkut, emails, baixarem músicas, comunidades virtuais, conversar com amigos e parentes distantes e etc. Então, com a colaboração e apoio da tutora do curso de Mídias nas Aulas de Matemática construimos e começamos a utilizar nas aulas de Matemática, o blog como um desafiador e envolvente recurso pedagógico. Conhecendo um pouco a história de vida, de moradia e do poder aquisitivo dos/as alunos/ as, resolvemos fazer um blog que tivesse uma variedade de informações, de forma a seduzir os jovens e adultos para um aprendizado com outras possibilidades em especial, o aprendizado de conteúdos de Matemática.

Esta narrativa nos revela que o blog deve ser utilizado como meio para conhecer, aprender e socializar as informações tanto para o/a professor/a, o/a aluno/a e a família. Coelho (2008), ao discutir os limites e possibilidades das tecnologias digitais na Educação de Jovens e Adultos (EJA), argumenta que "Inserir alunos jovens e adulto populares em ambientes informatizados em instituições educacionais de maneira sistematizada é, no mínimo, uma chance a mais de tentar 'dar vez e voz' aos excluídos de gerações e gerações" (COELHO; CRUZ, 2008, p. 56).

A questão da utilização das TICs na EJA passa por um processo de produção de saberes docentes ainda muito pouco explorado e pesquisado.

\section{Educação Matemática na EJA}

De acordo com os Parâmetros Curriculares Nacionais (PCNs) (BRASIL, 1998), o ensino da Matemática na EJA visa abordar questões que envolvam a economia, política, ética, meio ambiente, pluralidade cultural, saúde, família 
e outros aspectos e ainda levar o/a aluno/a a identificar a Matemática nestas adversidades como assim relata:

Identificar os conhecimentos matemáticos como meios para compreender e transformar o mundo à sua volta e perceber o caráter intelectual, característico da matemática, como aspecto que estimula o interesse, a curiosidade, o espírito de investigação e o desenvolvimento da capacidade para resolver problemas (BRASIL, 1998, p.61).

\section{Ainda segundo os PCNs,}

A Matemática pode dar sua contribuição à formação do cidadão ao desenvolver metodologias que enfatizem a construção de estratégias, a iniciativa pessoal, o trabalho coletivo e a autonomia advinda da confiança na própria capacidade para enfrentar desafios (BRASIL, 1998, p. 27)

Nesse contexto, se faz necessário que a escola contribua para o desenvolvimento de habilidades que permitam analisar e modificar situações do cotidiano dos/as alunos/as, o que implica na adoção de abordagens que contemplem temas transversais, uma vez que a escola deve colaborar para o desenvolvimento de capacidades que permitam ao/a aluno/a intervir na realidade para transformá-la. Assim, cabe ao/a professor/a, a tarefa de ressaltar o papel do/a aluno/a que se pretende formar.

Portanto a disciplina deve ser trabalhada de forma dinâmica, procurando levar os alunos e alunas a aplicarem os conhecimentos matemáticos a partir de seu cotidiano, superando-se o estudo de forma mecânica, no qual costumam predominar o decorar nomes, regras e técnicas que na vida real não têm nenhum significado, pois: "Quando a capacidade de refletir é deixada de lado na prática educacional, o que se produz é um indivíduo incapaz de raciocinar logicamente, que não poderá, evidentemente, refletir de maneira crítica e autônoma" (BRASIL, 1998, p. 27).

Rubem Alves indica que:

As escolas existem: não para ensinar as respostas, mas para ensinar as perguntas. As respostas nos permitem andar sobre a terra firme. Mas somente as perguntas nos permitem entrar pelo mar desconhecido [...]. A tarefa primordial do professor é: seduzir o aluno para que ele deseje, e, desejando, aprenda (ALVES, 2004, p. 58).

Num mundo globalizado em que as mudanças acontecem de forma acelerada, a informação e a comunicação ocupam lugar de prestígio, e o computador torna-se uma poderosa ferramenta para a construção do aprendizado, o que vem contribuir para uma educação inclusiva e de qualidade, assegurando a todos e todas a igualdade de oportunidades para o acesso e apropriação do conhecimento.

O trabalho pedagógico a ser desenvolvido numa turma de EJA requer esforços constantes no sentido de criar atividades contextualizadas, abordando assuntos e temas do cotidiano dos jovens e adultos. A necessidade deles/as é a compreensão e alfabetização, interpretar ações e operar cálculos do dia-a-dia, ou seja, serem capazes de viver em sociedade de forma a não serem alienados e marginalizados, mas inseridos no meio. Nas propostas curriculares de Matemática, Ciências e Artes para EJA relatam: "A participação da comunidade na escola, de modo que o conhecimento aprendido resulte em maior compreensão, integração e inserção no mundo e a certeza de que todos são capazes de aprender" (BRASIL, 2002, p. 7).

O ponto principal do trabalho desenvolvimento no blog foi definir saberes matemáticos que pudesse colaborar na formação educacional, política e social dos jovens e adultos. 
Assim, uma busca incansável por atividades, jogos educativos e temas centraram todos os esforços para, além disso, tentar captar as necessidades e transformá-las em assuntos de pauta nas aulas de Matemática se tornou meta para o desenvolvimento do blog.

Por conseguinte, o Brasil tem uma dívida histórica a ser reconhecida e resgatada pela própria constituição do Estado, cujo papel atualmente é outro: o de promover a inclusão. E como exemplo dessa ação de política anti-discriminatória e inclusiva podemos citar as leis anti-racismo, os PCNs que apontam a temática, a Lei Federal 10.639/2003 que torna obrigatório o ensino sobre a história e cultura africana e afro-brasileira nas escolas do país, ou mesmo a Lei Orgânica do Município de Uberlândia (MG), que em seu artigo 165, estabelece o combate a discriminação racial. Estas ações vêm de encontro aos resultados divulgados pelo Instituto de Pesquisa Econômica e Aplicada (IPEA) apontando que:

As diferenças raciais, contudo, são muito marcantes: os negros e negras estão menos presentes nas escolas, apresentam médias de anos de estudo inferiores e taxas de analfabetismo bastante superiores. As desigualdades se ampliam quanto maior o nível de ensino. No ensino fundamental, a taxa de escolarização líquida - que mede a proporção da população matriculada no nível de ensino adequado à sua idade - para a população branca era de 95,7 em 2006; entre os negros, era de 94,2. Já no ensino médio, essas taxas eram respectivamente, 58,4 e 37,4 . Isto é, o acesso ao ensino médio ainda é bastante restrito em nosso país, mas significativamente mais limitado para a população negra, que, por se encontrar nos estratos de menor renda, é mais cedo pressionada a abandonar os estudos e ingressar no mercado de trabalho (IPEA, 2008, p. 107).
A estatística mostra que no país é grande o número de brasileiros/as que não têm e não tiveram acesso à escola ou que a abandonaram antes de completar seus estudos. Os dados apresentados acima vêm de encontro à realidade da escola, fazendo-se urgentes e necessárias ações que visem minimizar a problemática, e é com este intuito que foi proposto o tema da culinária africana aliada a conteúdos de Matemática e que surgiu a partir de um projeto que estava em andamento na escola. Teve por finalidade conhecer as comidas típicas do continente africano que estão na mesa do brasileiro como cultura e heranças do povo africano que estão presentes no nosso cotidiano. A escola teve um papel fundamental no desenvolvimento do projeto cedendo o espaço físico que foi o laboratório de informática, entendendo as reais necessidades dessa turma da EJA.

Tendo em vista o estudo divulgado pelo Instituto Brasileiro de Geografia e Estatística (IBGE) de que a população brasileira é constituída de 91.051 milhões de pessoas brancas e 96.794 milhões são de pretas sendo que destes, 14.517 milhões são pretas e 82.277 miIhões são pardas (IBGE, 2010). E ainda, por o Brasil apresentar um quadro desolador de analfabetos em todo o seu território nacional sendo que $9,7 \%$ das pessoas com 15 anos ou mais não sabem ler nem escrever, isso corresponde a um contingente de 14,1 milhões de pessoas analfabetas. Sendo que a maioria dos que estão fora da escola em todas as faixas etárias são de pessoas pretas e pardas o que representa o dobro de analfabetos observados em relação à população branca, isso representa $13,3 \%$ de pretos e $13,4 \%$ de pardos contra $5,9 \%$ dos brancos o que demonstra uma enorme desigualdade social no país. 
Nesse contexto, o projeto teve o propósito de estudar a culinária africana aliada às várias possibilidades de aprender e aplicar conteúdos da matemática em situações reais do dia-a-dia do aluno. A escolha deu-se em virtude de saber que a cozinha é um laboratório onde os experimentos são realizados com as diversas receitas na perspectiva de ofertar um aprendizado que tenha significado para os jovens e adultos que estão conectados as novas formas de aprender.

Por outro lado, a culinária brasileira é rica, saborosa e diversificada. Cada recanto do país tem em seu cardápio pratos típicos, preparados de acordo com os ensinamentos adquiridos das tradições, que foram passadas ao longo das gerações. Dentre os pratos feitos na cozinha do brasileiro encontra-se os que são oriundos da culinária africana e, geralmente a população desconhece a sua origem.

Comer, não significa somente alimentar-se. $\mathrm{O}$ fato de sentar-se à mesa e compartilhar um alimento estabelece um diálogo por meio de um ritual, ocasião em que acontece a transmissão de cultura, costumes, vestuário, culinária dentre outras, de um povo. Como afirma o folclorista brasileiro Câmara Cascudo:

O significado da comida ultrapassa o simples ato de alimentar-se. São muitas as tradições que consideram a hora da refeição como semi -sagrada, de silêncio, compostura e severidade. Comer junto é aliar-se, a palavra companheiro vem do latim cum panis: de quem compartilha o pão [...]. A arte de comer, cerimonial festivo e íntimo, é um patrimônio que orgulha o homem, distinguindo-o do gorila, do orangotango e do chimpanzé, senhores de uma norma nutricionista bem mais superior à dos humanos. Comer é um ato orgânico que a inteligência tornou social. Todo animal sabe escolher e saborear seu alimento (CASCUDO, 1983, p. 77).
Nesta perspectiva, os conteúdos da Matemática começam a incorporar em seus estudos a questão cultural, que está focada nos fundamentos da Etnomatemática. E tem por intuito valorizar e divulgar a produção de saberes matemáticos praticados por outros grupos sociais, por considerar que estes saberes são produzidos historicamente. Como afirma D 'Ambrósio (1993, p. 120): "Aprender não é um mero domínio de técnicas, de habilidades, nem a memorização de algumas explicações teóricas, mas a capacidade de explicar, de apreender e compreender, de enfrentar, criticamente, situações novas".

Portanto, a Etnomatemática se apresenta como uma alternativa viável para o ensino da Matemática por fundamentar sua abordagem no encadeamento entre a cultura dos alunos e alunas e o conhecimento formal. E ainda, que os conhecimentos matemáticos existem em todas as culturas.

Esse é o papel da escola, promover a reflexão sobre a cultura, facilitar o acesso as novas tecnologias e a formação completa dos jovens e adultos. A escola deve ser um espaço de produção de conhecimentos e de interação social, oportunizando a formação de sujeitos críticos, solidários e participativos, logo sendo justa sua parceria com o trabalho do blog nas turmas de EJA.

\subsection{A Escola}

Este trabalho foi realizado numa Escola Municipal localizada na periferia da cidade de Uberlândia (MG), com 30 anos de atuação desde sua inauguração, atende nos três turnos, alunos/as oriundos do bairro e adjacências do ensino fundamental e da EJA. Uma das características da escola, por sua idade, é que vários alunos/as são filhos/as de ex-alunos/as e 
que podem contar para seus filhos e filhas as mudanças ocorridas tanto na escola quanto no bairro e na cidade como um todo.

Para proporcionar aos alunos e alunas um ensino de qualidade, a escola passou a se equipar de materiais tais como livros, computadores, jogos, televisão, vídeo e data show. Também ofereceu cursos de formação continuada aos profissionais da escola, de forma que tanto o/a aluno/a como o/a professor/a tivesse acesso adequado aos recursos pedagógicos e em particular aos tecnológicos, buscando um aprendizado mais próximo da realidade dos jovens e adultos e um reflexo satisfatório tanto na sua vida pessoal quanto profissional.

\subsection{Os Alunos e Alunas}

Os alunos e alunas, moradores na periferia da cidade, com baixo poder aquisitivo, tem acesso restritos aos conhecimentos, e portanto o computador passou a ser um importante, interessante e adequado instrumento para ampliar sua bagagem sócio, cultural e educativa.

Porém, o computador era explorado somente para navegar em sites como: programas de bate papo, páginas de relacionamento, emails, baixar e ouvir músicas e outros.

Daí, era urgente uma intervenção pedagógica do/a professor/a no sentido do/a aluno/a ter outro olhar sobre o papel das mídias, em especial do computador, na sua formação enquanto cidadão/ã. Havia uma grande necessidade de incluir educativamente, fazer com que as aulas de informática não fossem apenas uma diversão recreativa, mas um momento de aprendizado. E, assim o Laboratório de Informática passou ser o local mais desejado e esperado pelos jovens e adultos, sempre com muita euforia e motivação para aprender Matemática de uma forma diferente.
Muitos alunos e alunas da EJA nunca tiveram acesso ao computador, o mouse era um instrumento desconhecido e vários alunos/as não sabiam nem como manuseá-lo. Mas como as barreiras são feitas para serem quebradas, destruídas, aos poucos eles/as foram se familiarizando e passaram compreender que o computador era muito mais um amigo, um recurso pedagógico interessante, agradável e útil do que um inimigo digital.

\subsection{Estruturando os Blogs}

A partir dos relatos dos jovens e adultos (alunos) sobre sua história de vida, de moradia e poder aquisitivo, decidimos fazer dois blogs, um para as turmas do oitavo ano e um para as turmas do nono ano, que abordassem um universo variado de conhecimentos de forma a proporcionar aos alunos e alunas a descoberta de outros saberes e sabores, usando o computador para aprender Matemática e conhecer e ressignificar os saberes da cultura africada e culinária africana.

Nos blogs foram postados vídeos, fotos, textos diversos, dicas de estudos, slides, sites, desafios, jogos, comentários dos alunos e alunas, atividades e divulgações de eventos da escola. As atividades eram colocadas nos blogs $e$ os estudantes tinham que reescrevê-las no caderno e respondê-las. A professora regente avaliava os/as alunos/as durante o desenvolvimento dos trabalhos na sala de informática, nas atividades no caderno com as cópias e as respostas e nos blogs com os comentários. A utilização de um ambiente virtual (blog) possibilitou uma aproximação dos estudantes com essa nova forma de comunicação e informação e produção de conhecimento que é a internet, a cultura digital. Além de provocar e estimular os estudantes a participar da produção dos 
saberem matemáticos na utilização dos jogos online e das atividades que eram postadas.

Em uma das atividades, apresentamos aos estudantes um vídeo sobre a produção caseira do sabão e do detergente. Os alunos e alunas assistiram o video e em seguida anotaram a receita no caderno fazendo as conversões de medidas da seguinte forma: o que estava em litros (I) seria passado para mililitros $(\mathrm{ml})$ e 0 que estava em quilos $(\mathrm{kg})$ seria passado para gramas ( $g$ ). Mesmo sendo simples esta conversão, muitos alunos e alunas tiveram grandes dificuldades. Nas figuras 1 e 2 é possível observar a estrutura e a aparência dos blogs:

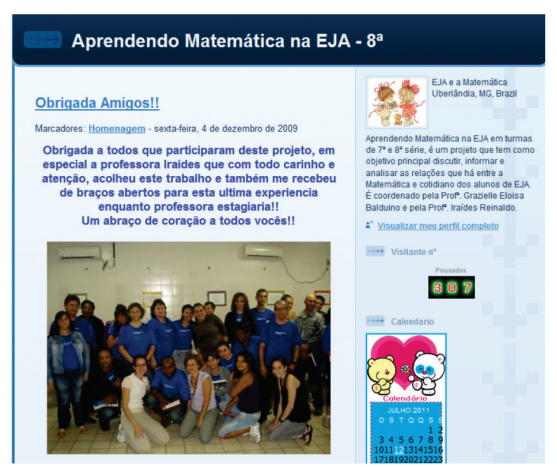

FIGURA 1 - Blog do Nono Ano - EJA FONTE: Arquivo da pesquisa.

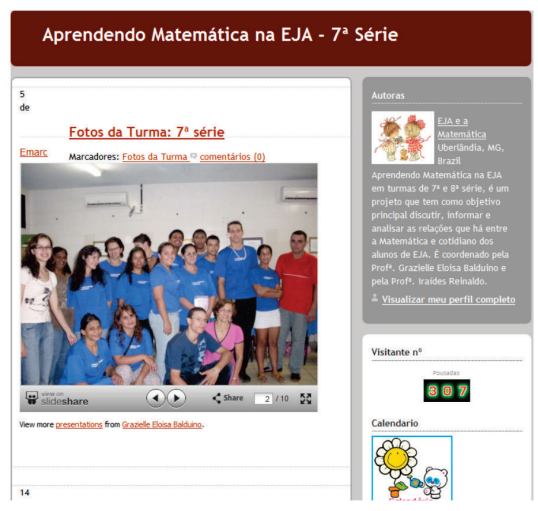

FIGURA 2 - Blog do Oitavo Ano - EJA FONTE: Arquivo da pesquisa.
Todas as atividades na sala de informática foram registradas por meio de fotografias. Cada encontro, os/as alunos/as postavam comentários sobre as atividades. Vários jovens e adultos comentaram que utilizavam o blog fora da escola, no trabalho, em casa e em lan house. Alguns trabalhos exigiam que primeiro os alunos e alunas copiassem no caderno e depois respondessem tanto no caderno quanto nos blogs. Assim treinavam a escrita que é um dos grandes problemas enfrentados pelos/as professores/as da EJA.

\subsection{Interação Alunos, Alunas e o Blog}

Ao informar para os/as alunos/as a criação do blog, todos ficaram entusiasmados e encantados com a proposta. Imediatamente começaram a acessá-lo tanto na escola quanto fora dela, em casa, no trabalho ou em lan house. A participação foi ativa dos jovens e adultos alunos com comentários sobre as atividades e também dos vídeos postados pela equipe do projeto e ainda sugestões de sites de jogos educativos e sites de informação.

A maioria dos textos sobre educação alimentar e culinária afro-brasileira foram lidos e comentados no blog pelos alunos e alunas. Nas duas turmas foi possível desenvolver o mesmo tema e ter a aprovação de ambas, socializando as descobertas com a família, o que contribuiu para um maior envolvimento e cumplicidade entre todos/as.

Assim, enquanto um programa de alfabetização de jovens de adultos da EJA, que por algum motivo não concluíram o ensino fundamental regularmente, acaba não atendendo todos os vieses da Educação como: desenvolver atividades complementares, incluir digi- 
talmente, discutir assuntos de interesse geral como economia, política e oportunizar o descobrimento e o entendimento da cultura. Por isso, a importância deste projeto para esses alunos e alunas, mais do que mostrar a ferramenta (computador) foi aprender como se usa e onde usá-la.

A seguir, os comentários dos/as alunos/as sobre o material postado no blog que esteve e ainda está disponível para consulta. Observa-se que a fala dos jovens e adultos da oitava e sétima serie do ensino fundamental da EJA só vem reforçar a ideia de que é necessário e urgente oferecer possibilidades de aprendizagem aos alunos e alunas, utilizando o computador e/ou o papel:

Nossa! Amei, ficou muito show o blog. Todos os dias eu vou entrar só pra ver as novidades (A1) 12 .

Esse blog ficou muito interessante, gostei muito de ler o estatuto da criança e do adolescente, aprendi sobre nossos direitos e deveres e o melhor, de uma forma divertida! (A2).

A internet é uma boa ferramenta de ensino para quem sabe utilizar, esse blog é uma prova disso, é um sucesso. Quero deixar aqui meus parabéns (A3).

Eu achei o vídeo do Homem que calculava muito interessante e, que ajuda a gente a entender melhor a matemática de uma forma bem legal. E também nos motiva a estudar mais e a gostar mais da Matemática (A4).

O estatuto da criança e do adolescente me ensinou que temos muitos direitos que devem ser respeitados, e deveres que devem ser cumpridos. Gostei muito do blog, professora. Parabéns (A5).

Jogar o sudoku foi muito legal e viciante. Além de tudo exercita e desenvolve o racio-

\footnotetext{
${ }_{1}^{1}$ Para preservar a identidade dos alunos, utilizamos pseudôni$\operatorname{mos}\left(A_{1}, A_{2}, \ldots, A_{n}\right)$ para identificá-los.

2 Para diferenciar das citações foi adotado outro tipo de fonte para os comentários dos/as alunos/as.
}

cínio, o que é muito proveitoso para quem gosta de ultrapassar os seus limites (A6).

Adorei o blog, é muito show e está lindo. Adoro a matemática e com esse blog maravilhoso a matemática fica mais interessante. Parabéns (A7).

Jogar o calculando no blog foi muito divertido e interativo. Com os diversos jogos que ele possui dá para passar horas se divertindo, como por exemplo, o tangram (A8).

Eu gostei muito do tangram, pois é uma atividade de raciocínio e criatividade e gostei muito do blog, pois tudo que tem nele é muito interessante e legal (A9).

Percebe-se que o blog é um recurso tecnológico que encanta os jovens e adultos alunos e que provoca um envolvimento e um dinamismo nas aulas de Matemática e, portanto pode e deve ser usado na escola para contribuir na formação dos/as alunos/as enquanto cidadãos/ãs que vivem num mundo em constantes transformações tecnológicas.

\section{Considerações Finais}

Pesquisar materiais, elaborar atividades sobre o cotidiano dos alunos e alunas da EJA e estabelecer interfaces entre a escola e as mídias foram um dos desafios que ao longo deste proposto artigo pretendeu desafiar e vencer. Por outro lado, ministrar aulas para esses jovens e adultos alunos é procurar entender as mazelas e conflitos de uma escola de um bairro carente, onde o pouco que se faz já pode ser muito. Conhecendo a história de vida, a condição de moradia e o poder aquisitivo da comunidade, resolvemos fazer um blog que tivesse uma variedade de informações para seduzir os/as alunos/as ao aprendizado de conteúdos de Matemática.

A ideia do ambiente virtual de aprendizagem veio de encontro aos anseios da profes- 
sora, da escola, dos/as professores/as envolvidos no referido projeto e dos/as alunos/as das duas turmas. Alguns resultados mostraram que além de um envolvimento mais motivador de jovens e adultos alunos e satisfatórios com relação aos conteúdos da disciplina de Matemática, adquiriram novos conhecimentos acerca da culinária africana, aguçando também o senso crítico e a sensibilidade para as questões sócio-ambientais e culturais abordadas.

A culinária africana e as descendências na culinária mineira e até mesmo na culinária brasileira foi uma flecha lançada que pode ainda certar alvos cada vez mais longínquos. Desenvolver esse tema motivou a turma da oitava série da EJA a pesquisarem sobre receitas caseiras que tinham resquícios africanos. Os textos sobre a África e as comidas herdadas por nós brasileiros foram peça chave para enriquecer o conhecimento de todos principalmente dos jovens e adultos.

\section{Referências}

ALVES, R. Ao Professor, com o Meu Carinho. Campinas: Versus, 2004.

BRASIL. Ministério da Educação. Parâmetros Curriculares Nacionais: ensino fundamental. Brasília, 1998.

BRASIL. Ministério da Educação. Propostas Curriculares Para Educação de Jovens e Adultos: segundo seguimento do ensino fundamental $5^{\mathrm{a}}$ a $8^{\mathrm{a}}$. Brasília, 2002. V. 3.

CASCUDO, L. da C. História da Alimentação no Brasil. Resenha de Luiza Larangeira da Silva Mello. In: ROTEIROS e Descobrimentos. [S.I.: s.n.], [2010?]. Disponível em: <www.históriaecultura.pro.br> Acesso em: set. 2010.

COELHO, S.L.B.; CRUZ, R.M.R. Limites e Possibilidades das Tecnologias Digitais na Educação de Jovens e Adultos. [S.I.: s.n.], 2008. Trabalho Apresentado no GT18 da 31. Reunião Anual da ANPED em 2008, Caxambú, BR-MG. Disponível em: <http://www.anped.org.br/reunioes/31ra/1trabalho/ GT18-5049--Int.pdf> Acesso em: 23 set. 09.

D’AMBRÓSIO, U. Etnomatemática: arte ou técnica de explicar e conhecer. São Paulo: Ática, 1993. 
IBGE. Síntese de Indicadores Sociais: uma análise das condições de vida da população brasileira. Estudos \& Pesquisas: informação demográfica e socioeconômica, Rio de Janeiro, n. 27, 2010. Disponível em: <http://www.ibge.gov.br/home/estatistica/populacao/condicaodevida/indicadoresminimos/sinteseindicsociais2010/SIS_2010.pdf> Acesso em: jul. 2011.

IPEA. Retrato das Desigualdades de Gênero e Raça. 3. ed. Brasília, 2008. Disponível em: <http:// www.ipea.gov.br/sites/000/2/destaque/Pesquisa_Retrato_das_Desigualdades.pdf> Acesso em: jul. 2011.

Submetido para avaliação em 12 de novembro de 2013.

Aprovado para publicação em 19 de agosto de 2014.

Grazielle Eloísa Balduino: Universidade Federal de Uberlândia - Uberlândia - MG - Brasil. Email: balduino.grazielle@gmail.com

Arlindo José de Souza Junior: Universidade Federal de Uberlândia - Uberlândia - MG - Brasil. Email: arlindoufu@ gmail.com

Iraídes Reinaldo da Silva: Universidade Federal de Uberlândia - Uberlândia - MG - Brasil. Email: iraidesrs@gmail. com 